\title{
Oecologia
}

\section{A naturally heterogeneous landscape can effectively slow down the dispersal of aquatic microcrustaceans \\ --Manuscript Draft--}

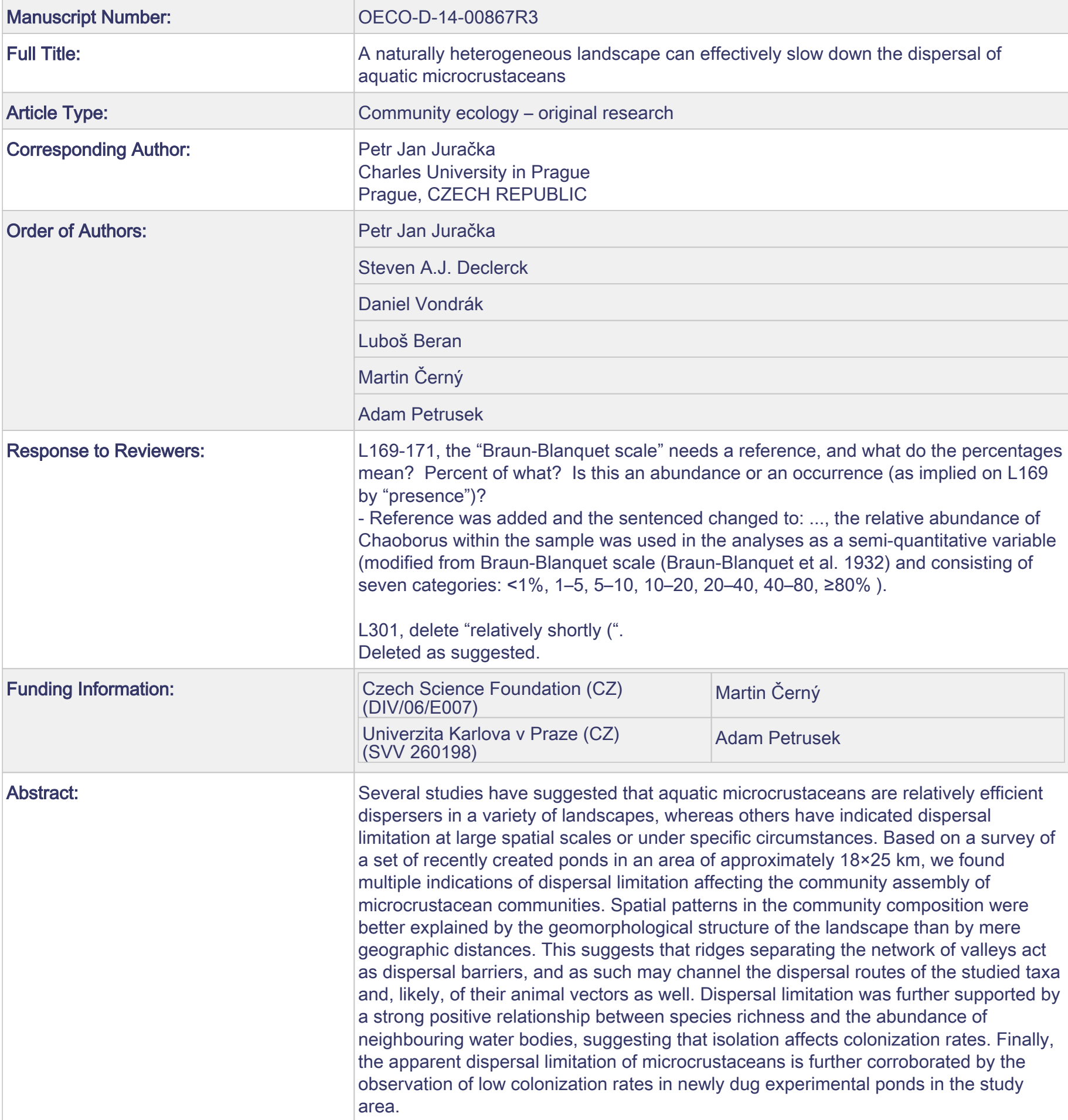




\section{A naturally heterogeneous landscape can effectively}

\section{2 slow down the dispersal of aquatic microcrustaceans}

3 PETR J. JURAČKA ${ }^{1}$, STEVEN A. J. DECLERCK ${ }^{2}$, DANIEL VONDRÁK ${ }^{1,4}$, LUBOŠ

$4 \quad$ BERAN $^{3}$, MARTIN ČERNÝ $^{1}$, ADAM PETRUSEK $^{1}$

5

61 Charles University in Prague, Faculty of Science, Department of Ecology, Viničná 7 ,

7 Prague 2, CZ-128 44, Czech Republic; GSM +420723119339; juracka@ natur.cuni.cz

92 Netherlands Institute of Ecology, Postbus 50, 6700 AB Wageningen, The Netherlands;

3 Agency for Nature Protection and Landscape Conservation of the Czech Republic,

Kokořínsko - Máchův kraj Protected Landscape Area Administration, Česká 149,

13 Mělník, CZ-276 01, Czech Republic;

14

4 Charles University in Prague, Faculty of Science, Institute for Environmental Studies, Benátská 2, Prague 2, CZ-128 44, Czech Republic;

KEYWORDS: zooplankton dispersal; dispersal limitation; metacommunity ecology; microcrustaceans; dispersal barriers;

Author Contributions: LB and AP originally formulated the idea. PJJ and LB conducted the fieldwork. DV and MČ conducted the field experiment. PJJ and DV analyzed the samples. PJJ, SAJD and AP proceeded the statistical analyses. PJJ, AP and SAJD wrote the manuscript. 


\section{ABSTRACT:}

Several studies have suggested that aquatic microcrustaceans are relatively efficient dispersers in a variety of landscapes, whereas others have indicated dispersal limitation at large spatial scales or under specific circumstances. Based on a survey of a set of recently created ponds in an area of approximately $18 \times 25 \mathrm{~km}$, we found multiple indications of dispersal limitation affecting the community assembly of microcrustacean communities. Spatial patterns in the community composition were better explained by the geomorphological structure of the landscape than by mere geographic distances. This suggests that ridges separating the network of valleys act as dispersal barriers, and as such may channel the dispersal routes of the studied taxa and, likely, of their animal vectors as well. Dispersal limitation was further supported by a strong positive relationship between species richness and the abundance of neighbouring water bodies, suggesting that isolation affects colonization rates. Finally, the apparent dispersal limitation of microcrustaceans is further corroborated by the observation of low colonization rates in newly dug experimental ponds in the study area.

\section{INTRODUCTION:}

Dispersal limitation and its impact on the community assemblage of isolated natural communities remains an intensively studied topic since the original formulation of the Island Biogeography Theory (MacArthur and Wilson 1967). Organisms with limited dispersal capabilities in particular should be studied in a regional rather than local context (see Hanski 1998, Leibold and Norberg 2004). Inhabitants of inland aquatic habitats, which are assumed to be physically more separated than terrestrial environments, have been reported to have larger dispersal capacities than terrestrial taxa of the same taxonomic groups (Kappes et al. 2014). Within the terrestrial realm, spatial structuring at very local scales is particularly obvious for soil organisms (e.g., Jiménez et al 2014), which are usually more dispersal limited 
50

51

than their above-ground relatives (Lindo and Winchester 2009). However, the majority of terrestrial passive dispersers, including plants (e.g, Auffret and Plue 2014, Soons and Ozinga 2005, Nathan and Muller-Landau 2000) and various invertebrates (see review Bell et al. 2005), can be quite effectively transported by wind or animal vectors. Such taxa tend to be more dispersal limited when they are habitat specialists (e.g., Ellis 2012, Löbel et al. 2006, Brunet et al. 2011) or at biogeographic rather than regional scales (e.g., Gonçalves-Souza et al. 2014).

Passive dispersal is one of the key adaptations of life in isolated freshwater habitats (see Maguire 1963), and has been studied in a considerable number of aquatic invertebrates (see Beisner et al. 2006, Bohonak and Jenkins 2003) and plants (e.g., Alahuhta et al. 2014, Viana et al. 2014). Microcrustaceans, especially cladocerans and copepods, are frequently studied model groups both in the field and in outdoor mesocosm experiments. Most studies on microcrustaceans have focused on relatively small spatial extents (at the scale of kilometres or less), and have found microcrustaceans to be efficient dispersers (e.g., Cohen and Shurin 2003; Michels et al. 2001). On the contrary, at very broad spatial scales (hundreds to thousands of kilometres) a limited number of studies have suggested some level of dispersal limitation (e.g., De Bie et al. 2012; Zhai et al. 2015). Under some specific circumstances, evidence of dispersal limitation at smaller spatial scales has also been reported from both experiments (Jenkins 1995) and field-based observational studies (Soininen et al. 2007). At intermediate scales (tens of kilometres), Declerck et al. (2011b) found growing spatial structuring with increasing spatial scale. However, field studies assessing potential dispersal limitation among microcrustacean communities at such intermediary scales are rare. In our study, therefore, we evaluated to what extent dispersal of microcrustaceans to newly created aquatic habitats can be affected by landscape structures that may act as potential barriers for passive dispersal. Over an area of ca $18 \times 25 \mathrm{~km}$, we studied 42 newly 
created fishless and spatially clustered pools (Fig. 1) in a landscape with four important characteristics: 1) a lack of large water bodies, 2) low connectivity among aquatic habitats; 3) a relatively low density of waterfowl (Št'astný et al. 2006), known to be one of the most important vectors of microcrustacean dispersal (Figuerola and Green 2002); and 4) the presence of steep canyons that can restrict the movement of dispersal vectors, including both waterfowl and terrestrial mammals. We focused on the species richness and composition of three major taxonomic groups of microcrustaceans (cladocerans, copepods, and ostracods).

In this naturally fragmented landscape, we hypothesized that the local species richness and composition of microcrustaceans should be structured more by the landscape structure (i.e., by natural spatial clustering and connectivity of the pools determined by the topography) than by pure geographical distance. Alternatively, if dispersal was unlimited we expected to observe only weak spatial patterns (if any), which could not be explained by the environment. Consequently, we also analyzed multiple statistical models that took into account the effects of potentially confounding environmental variables (which may be also spatially structured) and the species composition of invertebrate predators in the studied pools. Under the assumption of dispersal limitation, we also expected microcrustacean species richness in young pools to be related to the number of other aquatic habitats in the neighbourhood of the studied localities, which likely serve as the source of immigrant species (Louette and De Meester 2005). To evaluate this migration we also performed a field experiment with new pools dug directly in the study area. Three independent aspects make this study unique in the context of other spatially-oriented analyses of microcrustacean metacommunities: 1) the intermediate spatial scale, which is underrepresented in other studies; 2) the taxonomic coverage; and 3) the heterogeneous landscape structure.

\section{METHODS:}


100

101

102

103

104

\section{Study site and localities}

The 42 studied pools, selected according to the their position, size and age, are located within the Kokořínsko Protected Landscape Area (ca $18 \times 25 \mathrm{~km}, \mathrm{~N} 50^{\circ} 23^{\prime}-50^{\circ} 38^{\prime}$, E $14^{\circ}$ $24^{\prime}-14^{\circ} 42^{\prime}$ ), Czech Republic (Fig. 1). The local landscape is mostly forested and consists mainly of deep and narrow rocky valleys (with depths often reaching about $100 \mathrm{~m}$ ), the alluvial plains of two larger streams, as well as open meadows and fields located at higher elevations. Moreover, this area is characterized by a sparse stream network (due to the sandstone subsoil; see inset in Fig. 1) and scarcity of large aquatic habitats. Subsequently, there is also a relatively low abundance of waterfowl (Št'astný et al. 2006), key long-distance vectors of aquatic invertebrates and plants (Figuerola and Green 2002). The pools were created between 1997 and 2004 for conservation purposes, to provide suitable habitats for vulnerable amphibian, invertebrate and macrophyte taxa. Most of them (34 pools, i.e., 81\%) were new, the remaining ones ( 8 pools, 19\%) were renewed at places where a pool or a wetland had been located in recent decades but more recently had no open-water habitat remaining.

The pool surface areas spanned several orders of magnitudes (see Supplementary Table S1), with maximum values per pool in the studied years (2005 \& 2006) varying from 0.5 to $2400 \mathrm{~m}^{2}$ (median $150 \mathrm{~m}^{2}$ ). Maximum pool depths varied from 0.2 to $2 \mathrm{~m}$ (median 0.85 $\mathrm{m})$. Seven pools are connected to very small streamlets, while the remainder are not connected to any running water, even during occasional spring floods. Two of the pools occasionally dry out if the groundwater level is too low in summer; all of them freeze over in winter. All pools were intentionally kept fishless for the whole study period to promote the diversity of other animal and plant taxa. All also contained at least some macrophyte stands or littoral vegetation. More details on the basic environmental parameters of each pool are given in Supplementary Table S1. 


\section{Field sampling and sample processing}

The pools were sampled in two consecutive years (2005-2006), three times per year: in spring (late April to early May), summer (July) and autumn (October to early November). Two pools were completely dry in summer 2006, and three samples were accidentally lost during the fieldwork; we thus processed altogether 252 samples. We used plankton nets with mesh sizes of 40 to $200 \mu \mathrm{m}$ to collect samples of microcrustaceans (cladocerans, copepods, and ostracods). The $200 \mu \mathrm{m}$ throwing net was used to collect samples from open water; a poleattached $100 \mu \mathrm{m}$ net was swept through the littoral vegetation (the finer mesh size ensuring that even the smallest chydorid cladocerans living in the vegetation were collected). These samples were preserved in $90 \%$ ethanol. Furthermore, we collected a formalin-preserved sample at every site (primarily for an independent analysis of rotifer species composition but also to validate the presence/absence of crustacean species). When the macrophyte cover of the pond area exceeded $25 \%$ but open water was also present, both $100 \mu \mathrm{m}$ and $200 \mu \mathrm{m}$ net samples were taken and inspected separately; results were then pooled for the respective pond during the data analyses. The plankton nets were carefully washed between sampling of different pools.

During each sampling, we measured water temperature, dissolved oxygen concentration, conductivity and $\mathrm{pH}$ with a multiparameter water quality probe (YSI 556 MPS, YSI Inc., Yellow Springs, USA) in the middle of the water column. However, only conductivity was used in further statistical analyses, as the other parameters substantially vary on a diurnal basis. Coverage of macrophytes was rated categorically, as low (up to $25 \%$ of the pool bottom), medium (25\%-75\%) and high (over 75\%). Pool depth and approximate surface area were also noted on each sampling date.

Chlorophyll a, nitrogen and phosphorus levels were not measured in 2005 and 2006, but we had the opportunity to measure these variables during a later sampling campaign in 
150 spring 2008, when all other measured characteristics and the overall appearance of the pools

151 were very similar to preceding years. In these samples, total nitrogen and total phosphorus

152 were analysed from water filtered through plankton net of $40 \mu \mathrm{m}$ mesh size to remove large

153 seston. Nitrogen was then analysed by high temperature combustion using a Formac Total

154 Organic Carbon/Total Nitrogen analyzer (Skalar Analytical B.V., Breda, Netherlands). Total

155 phosphorus was measured colorimetrically after perchloric acid digestion according to

156 Kopáček and Hejzlar (1993). Chlorophyll a level was estimated in vivo with an AquaFluor

157 Fluorometer (Turner Designs, Sunnyvale, USA) and regarded as an indicator of the overall

158 trophic state and food availability for herbivorous microcrustaceans.

159 Microcrustacean species were identified under a light microscope and

160 stereomicroscope; copepods and ostracods were first treated with lactic acid to improve the

161 observation of detailed morphological traits. Whenever possible, animals were identified to

162 the species level using Amoros (1984), Flößner (2000), Šrámek-Hušek (1953), Meisch

163 (2000), Einsle (1996) and several unpublished keys on local fauna. In a few samples, too

164 small and therefore undeterminable copepod larvae were observed; these were not included in

165 further analyses. Whenever possible, at least 300 individuals from sub-samples of known

166 volume were identified from each sample, otherwise all specimens were identified and

167 counted. In open water samples, Chaoborus larvae were frequently found together with

168 microcrustaceans. As these predators are known to influence their communities substantially

169 (e.g., Jäger et al. 2011; Luecke and Litt 1987; Yan et al. 1991), the relative abundance of

170 Chaoborus within the sample was used in the analyses as a semi-quantitative variable

171 (modified from Braun-Blanquet scale (Braun-Blanquet et al. 1932) and consisting of seven

172 categories: $<1 \%, 1-5,5-10,10-20,20-40,40-80, \geq 80 \%)$.

173 To evaluate potential predation pressure on microcrustacean communities, we

174 simultaneously took samples of other macroinvertebrates living in the pools using a sweep 
175 net. These were always collected by the same person, applying a standardized sampling effort

176 (15 minutes sampling time per site). According to the local conservation policy, the sampling

177 of invertebrates had to be performed in order to maximize species richness but not to collect

178 macroinvertebrates quantitatively; thus neither the abundance nor biomass of individual

179 species could be quantified. Therefore, data on potential predatory taxa present in the sampled

180 pools, i.e., true bugs, dragonfly larvae, and aquatic beetles, were available as

181 presence/absence data only (Supplementary Table S2). All these taxa were identified by experts on the respective groups (see Acknowledgements).

\section{Data analysis}

The main aim of our analyses was to evaluate the extent to which colonization of newly constructed ponds by microcrustacean zooplankton may be constrained by dispersal limitation. This was achieved through multiple analyses of microcrustacean community composition data, as well as through the analysis of species richness patterns.

We created three sets of a priori spatial predictors based on pool locations and topography to evaluate potential dispersal limitation. Categorical dummy variables identified

191 clusters of pools (Fig. 1), within which we hypothesized among-pond dispersal is more frequent than among different clusters. In addition, for all pairs of the pools we computed two geographic distance matrices: a Euclidean distance matrix from geographical coordinates, and

194 a distance matrix that will further be referred to as the "valley distance" matrix. The latter 195 matrix comprised the shortest distances measured between each pair of pools following the 196 course of the main canyons and valleys. We hypothesized that this "valley distance" would 197 reflect connectivity among the localities by animal vectors (particularly terrestrial ones, which 198 we assumed play a major role in the area). These expectations were made a priori, without 199 any information on existing patterns of community differentiation. From both distance 
matrices, we calculated principal coordinates (PCoA) and used the most important orthogonal axes (vectors) with positive eigenvalues according to Borcard et al. (2011). Given that the probability for a pond to be reached by species may also depend on the availability of source populations in the neighbourhood, we also quantified the number of all lentic aquatic habitats present in a radius of $3 \mathrm{~km}$ around each pool (according to Louette et al. 2008). We applied partial redundancy analysis (RDA) and the variation partitioning procedure of Peres-Neto et al. (2006) to assess the unique explanatory power of each type of spatial predictor variable groups and the strength of their collinearities. Finally, we created a spatial RDA model composed of the variables with significant contributions.

To assess how much the community structure reflects the spatial structure and how much is confounded by variables related to other important ecological processes, we performed a second variation partitioning to challenge the spatial model with two categories of other explanatory variables: (1) a set of environmental variables (the 'environmental' matrix) and (2) variables representing features of the invertebrate predator communities (the 'predator' matrix).

The environmental matrix included key characteristics of the aquatic environment potentially affecting zooplankton communities, i.e. phytoplankton chlorophyll a concentration, concentration of total nitrogen and phosphorus, conductivity, a binary variable representing the historical presence/absence of a water body at the site, the age of the pool, macrophyte cover, surface area, and maximum depth. This matrix also included information on the characteristics of the immediate neighbourhood, i.e., the presence or absence of a connection to a stream, position of the pool at the bottom of a canyon or permanently shadowed area. The predator matrix contained variables reflecting various aspects of invertebrate predation pressure and consisted of predator species richness, semi-quantitative density of Chaoborus larvae in open water samples, and five variables representing the major 
axes of variation in the species composition of invertebrate predators (i.e. the five most important PCoA axes built from a Sørensen dissimilarity matrix that was calculated from predator presence-absence data).

Presence-absence data indicate the spatial distribution patterns of species. When based on abundance data, the interpretation of patterns of community differentiation may be confounded by the relative ecological success of species at sites, as well as possible sampling bias when using different mesh sizes. For this reason, we expected presence-absence data to be more straightforward for the interpretation of metacommunity patterns that had been caused by dispersal limitation (Declerck et al. 2011b). All RDA and variation partitioning analyses in this study were therefore based on microcrustacean presence-absence data. To avoid the problem of too many zeros in the presence-absence data (the so-called double-zero problem), we applied the procedure of distance-based redundancy analysis (Borcard et al. 2011; Legendre and Anderson 1999). We first compiled species lists for each site based on all observations of our two-year study period. We then used this presence-absence matrix to calculate a Jaccard distance matrix, and subsequently extracted principal coordinates which were then used as species variables in the redundancy and variation partitioning analyses. To prevent negative eigenvalues, we applied a Lingoez correction in these principal coordinate analyses. All continuous environmental explanatory variables were log-transformed prior to analyses. Prior to variation partitioning, we applied the AIC stepwise forward selection procedure according to Crawley (2007) on the environmental and predator variables, using the R function "step". Variation partitioning was computed using the functions "vegdist" and "varpart" of the R library vegan (Oksanen et al. 2011). Principal coordinate analysis was done using the function "pcoa" of the package ape (Paradis et al. 2004).

To identify and evaluate the most important variables affecting crustacean species richness, we constructed a regression tree relating local species richness with the entire set of 
explanatory and spatial variables. Regression trees are appropriate for exploring complex data including multiple and unknown interactions (e.g., Allen and Dodson 2011; Davidson et al. 2012). To construct the tree, we applied binary recursive partitioning using the $\mathrm{R}$ library tree (Ripley 2011); afterwards we reduced the model complexity by using the function "prune.tree" based on a cost-complexity measure according to Crawley (2007).

\section{Colonization experiment}

We complemented our survey with a colonisation experiment based on the expectation that colonization of newly created habitats represents a lower boundary of dispersal rates. We built a set of 20 experimental pools in an area of $120 \times 160 \mathrm{~m}$ in a meadow within the study area (Fig. 1). The pools had a circular shape of $5 \mathrm{~m}$ in diameter, with an average depth of ca $0.5 \mathrm{~m}$ and a surface area of approximately $10 \mathrm{~m}^{2}$. The bottom of the pools was covered by plastic foil to reduce variations in water level fluctuation among pools. Pools were filled with water from a nearby brook that had been double filtered through a plankton net (40 $\mu \mathrm{m}$ mesh). For the sake of other research objectives, half of the experimental pools were inoculated with 500 adult females of Daphnia curvirostris per pool (manuscript in preparation); these units were not taken into account for the present study. We were able to collect data from only 8 of the remaining pools because two dried out soon after the start of the experiment due to damage to the foil.

Sampling of the pools started four weeks after pool construction (July 2007). A 61 water sample from the whole water column was collected at multiple places in each pool using a tube sampler, and filtered through a plankton net with $40 \mu \mathrm{m}$ mesh size. Samples were then preserved with formalin. To avoid contamination, the equipment was carefully washed between sampling of different pools. For each pool, crustacean species composition (presence/absence) was analysed from six samples collected in the first year of the existence 
275 of the pool (collected in three-week intervals between August and December 2007), and five 276 samples from the second year (collected in ca two-month intervals between March and 277 December 2008).

In addition, we sampled all water bodies within a radius of $3 \mathrm{~km}$ of the colonisation experiment, assuming that these water bodies were the most likely candidate sources of 280 microcrustaceans colonizing the experimental pools (except for D. curvirostris, which could 281 colonize from adjacent inoculated pools). These water bodies consisted of five pools from cluster F (Fig. 1, no. 37-41; distance: 0.5-2 km), one small pond in a castle park (P1; distance: ca $3 \mathrm{~km}$ ) and a set of 5 interconnected shallow fishponds (P2; 0.2-2 ha; distance: 2-3 km). We are not aware of any other relevant freshwater habitats located closer than $6.2 \mathrm{~km}$ to the experimental area. We assessed the local species pool from these water bodies by sampling them once during the spring and once during the summer during the experiment, except for pools 37-41 that were regularly sampled in the framework of the survey described above.

\section{RESULTS:}

Microcrustaceans found in the pools

291 We identified 54 microcrustacean taxa (Supplementary Table S3): 30 species of cladocerans, 29215 cyclopoids, 1 calanoid, and 8 ostracods. The most common species were the cyclopoids 293 Eucyclops gr. serrulatus (40 pools) and Megacyclops viridis (26 pools), the cladocerans 294 Chydorus sphaericus (40 pools) and Simocephalus vetulus (30 pools), and the ostracods 295 Cypridopsis vidua (30 pools) and Notodromas monacha (28 pools). One of the cladocerans 296 found during this study, Daphnia hrbaceki, was recently described as a new species (Juračka et al. 2010), and the most common cyclopoid, E. gr. serrulatus, was shown to actually be a diverse species complex (Hamrová et al. 2012). 
The average number of species per sample reached 4.4, whereas the maximum species

300 count in a single sample was 13 . However, the cumulative species richness per pool over the

301 whole study period ranged from 7 to 21 species (mean 11.7; see Supplementary Table S1).

302 Pools created up to 2 years before the onset of the study $(n=17)$ already hosted relatively rich

303 microcrustacean communities (7-19 spp., median 12), and the species richness of this

304 category of young pools was not significantly lower or higher than that of older pools $(n=25$,

305 8-21 spp., median 11).

306

Variation partitioning of community composition

308 Valley distances were superior to Euclidean distances in explaining variation in the

309 microcrustacean community composition (adj. $\mathrm{R}^{2}$ of conditional effect: $7 \%, \mathrm{p}<0.005$ for the

310 former vs. $0.7 \%, p=0.24$ for the latter; results not shown). Valley distances (Fig. 2A; adj. $\mathrm{R}^{2}$

311 of the conditional effect: 6.7\%; $\mathrm{p}<0.005$ ), and a priori defined spatial clusters (Fig. 2A; adj.

$312 \mathrm{R}^{2}$ of the conditional effect: $4.0 \% ; \mathrm{p}=0.035$ ) each explained a significant portion of the

313 compositional variation independently. The conditional effect of neighbouring source habitats

314 was lower and insignificant (Fig. 2A; adj. $\mathrm{R}^{2}$ of the conditional effect: $1.0 \% ; \mathrm{p}=0.095$ ).

315 However, the number of neighbouring habitats was significantly collinear with both

316 previously mentioned spatial matrices (Fig. 2A; adj. $\mathrm{R}^{2}$ of the marginal effect: $2.6 \%$; $<$

317 0.005). Subsequently, we merged all three predictor variable categories into one matrix

318 (further referred to as the 'spatial context') and partitioned the crustacean community

319 variation among this matrix and the most parsimonious predictor matrices for pool

320 environment (consisting of the variables pool surface area and hydrological history) and

321 invertebrate predator communities (i.e., number of predator taxa). Each of the three matrices

322 (spatial, environmental, predator) explained the crustacean species composition significantly

323 when tested on their own (marginal effects: $\mathrm{p} \leq 0.005$; Fig. 2B). Spatial context explained a 
324 total of $11.7 \%(\mathrm{p}<0.005)$ of the community variation, of which $6.7 \%(\mathrm{p}<0.005)$ was unique

325 and of which 5\% was collinear with the other predictor variables. Environmental variables

326 explained a total of $7.4 \%(\mathrm{p}<0.005)$ of the community variation, of which $2.2 \%(\mathrm{p}<0.05)$

327 was collinear. Predator species richness explained $6.7 \%(\mathrm{p}<0.005)$ of the microcrustacean

328 species composition, but all of this variability was found to be collinear with the spatial and

329 environmental variables. Indeed, a strong positive association was found between pool

330 surface area and predator species richness (Fig. 3). The whole model explained $16 \%$ of the

331 microcrustacean community variation and was highly significant $(\mathrm{p}<0.005)$.

Species richness

The best regression tree (Fig. 4) explained $64 \%$ of the variation in local species richness. The strongest predictor of this tree, explaining $36 \%$ of species richness variation, was the number of lentic aquatic habitats within a $3 \mathrm{~km}$-radius around the target pools. The 20 pools surrounded by less than 8 potential source habitats hosted significantly fewer microcrustacean species than the remaining 22 pools (median values of 10 and 13.5 species, respectively). The latter group was further split into a group of 10 smaller, relatively species-

340 poor pools (surface area: $<200 \mathrm{~m}^{2}$; median of species richness: 12 species), and 12 larger 341 pools with higher species richness (median: 14 species). Macrophyte cover was identified as

342 the most important variable affecting the species richness in pools with low numbers of 343 nearby source habitats. Pools with a macrophyte cover lower than $25 \%$ of the pool surface

344 area had lower species richness (median: 9 species) than pools with a higher macrophyte 345 cover (median: 11 species). Pool surface area, the number of nearby source habitats, and macrophyte cover all showed positive associations with species richness (see Fig. 4). 
During the two surveyed seasons, the ensemble of experimental pools was colonized by a total of six microcrustacean taxa (Supplementary Table S4), two found very early after the start of the experiment and four additional ones in the course of the second year (Fig. 5). The number of taxa observed at any point in time was usually very low (Fig. 5). D. curvirostris, which most probably originated from the nearby inoculated pools, was found in four pools already during the first sampling, then colonizing one more pool one month later, and an additional one in the second year. Other early colonizers were the cladoceran Bosmina longirostris (found in two pools on the first sampling date) and juvenile copepods (in four pools; these, however, could not be identified to the species level). Copepod adults, identified as Mesocyclops leuckartii and Eucyclops gr. serrulatus, were found in the second year of the study (each in two pools). Additional taxa observed during the second year included one cladoceran (Scapholeberis mucronata, in two pools), and an ostracod (Notodromas monacha, eventually found in seven pools). All these species were also found in pools of the field survey (Supplementary Table S4).

\section{DISCUSSION:}

In a landscape characterised by scarce freshwater habitats located within valleys demarcated by steep slopes, we aimed to evaluate the extent to which the colonisation process

367 of microcrustacean communities in newly created pools may be hampered by dispersal

368 limitation. Three independent lines of evidence indeed suggest some level of dispersal

369 limitation: (1) A priori defined clusters of the pools, based on their location in canyons or

370 deep valleys, significantly predicted microcrustacean species composition. Also, valley

371 distances explained community composition substantially better than Euclidean distances

372 between pools. (2) Pools with more aquatic habitats in their vicinity contained more species

373 than more isolated ones, suggesting that microcrustacean communities in the pools are 
374 substantially influenced by dispersal from nearby sources. (3) In an outdoor colonization

375 experiment, only a very limited subset of the local microcrustacean species pool (6 out of 31

376 spp.) was able to successfully colonize newly created ponds within a time span of 1.5 years.

377 The degree to which a metacommunity of organisms is affected by dispersal limitation

378 depends on the age of the habitat, distances between habitat patches, and the presence and

379 spatial configuration of dispersal barriers, in addition to other important factors such as

380 overall landscape connectivity and the dispersal capabilities of the organisms under

381 consideration (Leibold et al. 2004). Our study is unique in that it addresses spatial community

382 patterns of relatively young microcrustacean communities at an intermediate geographic scale

383 (tens of kilometres). In contrast, most studies on young communities have so far been largely

384 experimental, based on the monitoring of community trajectories in mesocosms or newly dug

385 ponds within short time frames and at very local scales (e.g., Cohen and Shurin 2003; Jenkins

386 1995). Survey-based studies of cladoceran metacommunities at larger scales have mainly

387 been limited to an analysis of the spatial structure of older, established metacommunities

388 (e.g., Declerck et al. 2011b; Viana et al. 2014). Although experimental studies have often

389 documented the rapid colonization of newly created pond habitats at least by a regionally

390 occurring subset of crustacean zooplankton species (e.g., Cohen and Shurin 2003; Louette et

391 al. 2008; but see Jenkins and Buikema 1998), several survey-based studies have also revealed

392 indications of some degree of dispersal limitation in naturally occurring established

393 zooplankton metacommunities. For example, in studies of habitats spatially arranged in a

394 hierarchic manner, $\mathrm{Ng}$ et al. (2009) and Declerck et al. (2011b) reported an increased

395 signature of dispersal limitation with increasing spatial extent. Our study therefore fills a gap

396 by studying the signatures of dispersal limitation in recent pond habitats at larger than local

397 spatial scales. 
Studies comparing spatial patterns among organism groups have indicated weaker spatial patterning in zooplankton taxa when compared to larger-bodied passively dispersing organism groups such as macroinvertebrates and fish, but stronger patterning than in microorganisms (Beisner et al. 2006; De Bie et al. 2012; Shurin et al. 2009). For recently established pond habitats, our results suggest that the zooplankton assembly can be substantially affected by dispersal limitation, to such an extent that the signature of this dispersal limitation is still noticeable several years after pond creation. It should be noted, however, that our study may only be representative for pools and ponds in landscapes that are characterized by a low abundance of freshwater habitats and the presence of important dispersal barriers. Furthermore, at longer time scales, the impact of dispersal limitation might be weaker, and community composition will likely better reflect environmental conditions (the so-called "quorum effect"; see Jenkins and Buikema 1998), possibly mediated by priority effects (Allen et al. 2011).

Abiotic vectors, such as wind, rain or water currents, have occasionally been shown to play a role in the overland dispersal of crustacean zooplankton organisms at small spatial scales (e.g., Cacéres and Soluk 2002; Cohen and Shurin 2003; Sciullo and Kolasa 2012). Given the relatively large spatial scale of our study area and the low hydrological connectivity among pool habitats, animal vectors most likely played an important role in crustacean dispersal. The most important candidate vectors in the area are large mammals (e.g., Vanschoenwinkel et al. 2008b; Waterkeyn et al. 2010), and waterfowl (e.g., Figuerola and Green 2002); other animal groups reported to disperse freshwater crustaceans, such as amphibians (Vanschoenwinkel et al. 2008a) and large aquatic insects (Schlichting and Sides 1969; Van de Meutter et al. 2008), are probably less relevant. Large mammals, particularly roe deer and wild boar, are locally abundant (Beran et al. 1999), and their footprints were often observed at the edge of studied pools during the sampling. Despite relatively low 
waterfowl densities in the region when compared to the rest of the Czech Republic, we also frequently observed mallard ducks (Anas platyrhynchos) at the studied localities, known to disperse dormant stages of aquatic invertebrates (Green et al. 2002; Proctor 1964) and even living ostracods (Green et al. 2013). Thus, waterfowl may contribute to pool colonization, and the signs of dispersal limitation may rather represent the limited mobility of vectors among pools from different clusters than their overall scarcity.

The amount of community variation that was explained by local environmental variables was low. Such low explanatory power of environmental variables may occur when important latent environmental variation is missed by the survey, and when spatial processes influence the species composition more than species sorting (Padial et al. 2014). Furthermore, priority effects (Frisch and Green 2007) and habitat monopolization (De Meester et al. 2002; Louette et al. 2007) by first colonizers may also contribute to a poor match between environment and species composition (Jenkins and Buikema 1998; Schulz et al. 2012). Pool surface area and hydrological history of the habitat were the only abiotic environmental variables that we found to be significantly associated with microcrustacean community composition. The variation explained by these factors was, however, almost entirely collinear with the taxonomic richness of predatory invertebrates and spatial context (Figs 3 and 4). Indeed, ponds with a large surface area contain a more diverse invertebrate fauna than smaller ponds (Angeler and Alvarez-Cobelas 2005; Anusa et al. 2012; March and Bass 1995). Splitting the explained variability of the species composition into spatial and environmental contexts via variation partitioning based on eigenvector-based spatial filters (including PCoA used by us) has been recently disputed, as this approach may lead to inaccurate estimations of explained variability when inappropriately used (e.g., Diniz-Filho et al. 2012, Gilbert and Bennett 2010, Smith and Lundholm 2010)., After reviewing numerous variation partitioning studies, Soininen (2014) strongly suggested considering not only spatial 
448 and environmental matrices, but also biotic interactions, which may mask a species sorting

449 mechanism (i.e., the effect of the "environment fraction" on the species composition). In our

450 study, we indeed analysed data on predator presence that may have influenced the observed

451 communities substantially (e.g., Shurin 2001, Verreydt et al. 2012). Furthermore, our

452 conclusions that microcrustacean dispersal is limited in the studied heterogeneous landscape

453 are based not only on variation partitioning of the species composition, but also on the

454 analysis of species richness.

455 During our entire study, we detected a total of 54 taxa for the whole region under 456 consideration, which is in agreement with the only previous study on microcrustaceans in the 457 area (Omesová 2005), which reported 24 cladocerans and 16 copepods from 30 comparable 458 habitats. Regression tree analysis revealed that microcrustacean species richness in ponds was 459 best related to the number of other aquatic habitats in the immediate surroundings. This 460 pattern most likely reflects the decreasing likelihood of colonization of a pond with an 461 increasing degree of isolation. The pool area was the second most important factor 462 influencing microcrustacean species richness, with larger pools being more species-rich than 463 smaller pools. Populations in larger pools are less prone to extinction than populations in 464 smaller pools (Frisch et al. 2006) and have a higher probability of receiving dispersing 465 propagules than small patches (e.g., MacArthur and Wilson 1967). Larger pools may also 466 harbour higher microhabitat diversity and therefore provide higher niche diversity, allowing 467 the coexistence of higher numbers of species (March and Bass 1995). The positive association 468 between macrophyte cover and species richness indeed suggests an important influence of 469 microhabitat diversity for crustacean diversity in these ponds (e.g., Cornell and Lawton 1992; 470 Declerck et al. 2011a; Declerck et al. 2007; Shiel et al. 1998).

471 Despite the absence of active transport, documented colonization rates of 472 microcrustaceans colonizing new habitats are usually relatively high, at least at small to 
473 intermediate spatial scales (e.g., Frisch et al. 2012, Louette and De Meester 2005). Our study

474 demonstrates that in sufficiently complex landscapes with a low density of and connectivity 475 among waterbodies, microcrustacean communities may be substantially affected by dispersal

476 limitation, at least in the early stages of their existence. The application of distance measures 477 that take into account the landscape complexity, such as the "valley distance" used in our 478 case, can help elucidate scale-dependent biodiversity patterns.

479

480 ACKNOWLEDGEMENTS:

481 M. Šorf, J. Hotový and B. Nová helped in the field, J. Fott, V. Sacherová, M. Bláha, and M.

482 Šorf during species determination, Z. Juračková, M. Lulay and J. Vojta with assessing the 483 spatial distribution and maps. Statistical analyses could not have been done without the 484 important advice of P. Keil and V. Jarošík. Predator taxa - true bugs, dragonflies and aquatic 485 beetles were identified by the following specialists: P. Kment, T. Soldán, J. Dobiáš, D.

486 Boukal, J. Klecka and T. Ditrich. We thank R. Symonová for her useful advice on ostracod 487 identification. Two anonymous reviewers and J. Shurin provided useful comments to previous 488 versions of the manuscript. The study was funded by the EuroCORES/EuroDIVERSITY 489 project BIOPOOL (supported through the Czech Science Foundation project no. 490 DIV/06/E007), the Charles University in Prague (SVV 260198). 


\section{REFERENCES:}

Alahuhta J, Johnson LB, Olker J, Heino J (2014) Species sorting determines variation in the community composition of common and rare macrophytes at various spatial extents. Ecol Complexity 20: 61-68 doi: 10.1016/j.ecocom.2014.08.003

Allen MR, VanDyke JN, Cáceres CE (2011) Metacommunity assembly and sorting in newly formed lake communities. Ecology 92:269-275 doi: 10.1890/10-0522.1

Allen PE, Dodson SI (2011) Land use and ostracod community structure. Hydrobiologia 668:203-219 doi: 10.1007/s10750-011-0711-7

Amoros C (1984) Crustacés Cladocères. Bulletin mensuel de la Société Linnéenne de Lyon, vol 53, pp 72-145

Angeler DG, Alvarez-Cobelas M (2005) Island biogeography and landscape structure: Integrating ecological concepts in a landscape perspective of anthropogenic impacts in temporary wetlands. Environ Pollut 138:420-424 doi: 10.1016/j.envpol.2005.04.020

Anusa A, Ndagurwa HGT, Magadza CHD (2012) The influence of pool size on species diversity and water chemistry in temporary rock pools on Domboshawa Mountain, northern Zimbabwe. Afr J Aquat Sci 37:89-99 doi: 10.2989/16085914.2012.666378

Auffret AG, Plue J (2014) Scale-dependent diversity effects of seed dispersal by a wild herbivore in fragmented grasslands. Oecologia 175: 305-313 doi: 10.1007/s00442014-2897-7

Beisner BE, Peres-Neto PR, Lindstrom ES, Barnett A, Longhi ML (2006) The role of environmental and spatial processes in structuring lake communities from bacteria to fish. Ecology 87:2985-2991 doi: 10.1890/0012-9658(2006)87[2985:troeas]2.0.co;2

Bell JR, Bohan DA, Shaw EM, Weyman GS (2005) Ballooning dispersal using silk: world fauna, phylogenies, genetics and models. Bull Entomol Res 95:69-114 doi: 10.1079/BER2004350 
516 Beran L et al. (1999) Plán péče o chráněnou krajinnou oblast Kokořínsko - Mělník: Správa chráněných krajinných oblastí ČR - Správa CHKO Kokořínsko, p 80

Bohonak AJ, Jenkins DG (2003) Ecological and evolutionary significance of dispersal by freshwater invertebrates. Ecol Lett 6:783-796 doi: 10.1046/j.1461-0248.2003.00486.x

Borcard D, Gillet F, Legendre P (2011) Numerical ecology with R.- Springer New York

Braun-Blanquet J, Conard HS, Fuller GD (1932) Plant sociology; the study of plant communities. New York and London, McGraw-Hill book company, inc.

Brunet J, Valtinat K, Mayr ML, Felton A, Lindbladh M, Bruun HH (2011) Understory succession in post-agricultural oak forests: Habitat fragmentation affects forest specialists and generalists differently. Forest Ecol Manag 262:1863-1871 doi: 10.1016/j.foreco.2011.08.007

Cacéres CE, Soluk DA (2002) Blowing in the wind: a field test of overland dispersal and colonization by aquatic invertebrates. Oecologia 131:402-408 doi: 10.1007/s00442002-0897-5

Cohen GM, Shurin JB (2003) Scale-dependence and mechanisms of dispersal in freshwater zooplankton. Oikos 103:603-617 doi: 10.1034/j.1600-0706.2003.12660.x

Cornell HV, Lawton JH (1992) Species interactions, local and regional processes, and limits to the richness of ecological communities: a theoretical perspective. J Anim Ecol 61:112 doi: $10.2307 / 5503$ Seasonal and spatial hydrological variability drives aquatic biodiversity in a floodpulsed, sub-tropical wetland. Freshwater Biol 57:1253-1265 doi: 10.1111/j.1365- 
540 De Bie T, De Meester L, Brendonck L, Martens K, Goddeeris B, Ercken D, Hampel H, Denys

541

542

543

544

545

546

547

L, Vanhecke L, Van der Gucht K, Van Wichelen J, Vyverman W, Declerck SAJ (2012) Body size and dispersal mode as key traits determining metacommunity structure of aquatic organism. Ecol Lett 15:740-747 doi: 10.1111/j.14610248.2012.01794.X

De Meester L, Gómez A, Okamura B, Schwenk K (2002) The Monopolization Hypothesis and the dispersal-gene flow paradox in aquatic organisms. Acta Oecol 23:121-135 doi: 10.1016/S1146-609X(02)01145-1

Declerck SAJ, Bakker ES, van Lith B, Kersbergen A, Van Donk E (2011a) Effects of nutrient additions and macrophyte composition on invertebrate community assembly and diversity in experimental ponds. Basic Appl Ecol 12:466-475 doi: 10.1016/j.baae.2011.05.001

Declerck SAJ, Coronel JS, Legendre P, Brendonck L (2011b) Scale dependency of processes structuring metacommunities of cladocerans in temporary pools of High-Andes wetlands. Ecography 34:296-305 doi: 10.1111/j.1600-0587.2010.06462.x

Declerck SAJ, Vanderstukken M, Pals A, Muylaert K, De Meester L (2007) Plankton biodiversity along a gradient of productivity and its mediation by macrophytes. Ecology 88:2199-2210 doi: 10.1890/07-0048.1

Diniz-Filho JAF, Siqueira T, Padial AA, Rangel TF, Landeiro VL, Bini LM (2012) Spatial autocorrelation analysis allows disentangling the balance between neutral and niche processes in metacommunities. Oikos 121: 201-210 doi: 10.1111/j.16000706.2011.19563.x

Einsle U (1996) Copepoda: Cyclopoida: Genera Cyclops, Megacyclops, Acanthocyclops. SPB Academic Publishing 
564 Ellis CJ (2012) Lichen epiphyte diversity: A species, community and trait-based review.

565

566

567

568

569

570

571

572

573

574

575

576

577

578

579

580

581

582

583

584

585

586

587

588

Perspect Plant Ecol Evol Syst 14:131-152 doi: 10.1016/j.ppees.2011.10.001

Figuerola J, Green AJ (2002) Dispersal of aquatic organisms by waterbirds: a review of past research and priorities for future studies. Freshwater Biol 47:483-494 doi: 10.1046/j.1365-2427.2002.00829.x

Flößner D (2000) Die Haplopoda und Cladocera (ohne Bosminidae) Mitteleuropas. Backhuys Publishers, Leiden

Frisch D, Cottenie K, Badosa A, Green AJ (2012) Strong spatial influence on colonization rates in a pioneer zooplankton metacommunity. PLoS ONE 7:e40205 doi: 10.1371/journal.pone.0040205

Frisch D, Green AJ (2007) Copepods come in first: rapid colonization of new temporary ponds. Archiv Hydrobiol 168:289-297 doi: 10.1127/1863-9135/2007/0168-0289

Frisch D, Moreno-Ostos E, Green AJ (2006) Species richness and distribution of copepods and cladocerans and their relation to hydroperiod and other environmental variables in Doñana, south-west Spain. Hydrobiologia 556:327-340 doi: 10.1007/s10750-005$1305-\mathrm{z}$

Gilbert B, Bennett JR (2010) Partitioning variation in ecological communities: do the numbers add up? J Appl Ecol 47: 1071-1082 doi: 10.1111/j.1365-2664.2010.01861.x

Gonçalves-Souza T, Romero GQ, Cottenie K (2014) Metacommunity versus biogeography: A case study of two groups of Neotropical vegetation-dwelling arthropods. PLoS ONE 9: e115137 doi:10.1371/journal.pone.0115137

Green AJ, Figuerola J, Sánchez MI (2002) Implications of waterbird ecology for the dispersal of aquatic organisms. Acta Oecol 23:177-189 doi: 10.1016/S1146-609X(02)01149-9

Green AJ, Frisch D, Michot TC, Allain LK, Barrow WC (2013) Endozoochory of seeds and invertebrates by migratory waterbirds in Oklahoma, USA. Limnetica 32:39-46 
Hamrová E, Krajíček M, Karanovic T, Černý M, Petrusek A (2012) Congruent patterns of lineage diversity in two species complexes of planktonic crustaceans, Daphnia longispina (Cladocera) and Eucyclops serrulatus (Copepoda), in East European mountain lakes lakes. . Zool J Linn Soc-Lond 166:754-767 doi: 10.1111/j.10963642.2012.00864.x

Hanski I (1998) Metapopulation dynamics. Nature 396: 41-49 doi:10.1038/23876

Jäger IS, Hölker F, Flöder S, Walz N (2011) Impact of Chaoborus flavicans - predation on the zooplankton in a mesotrophic lake - a three year study. Int Rev Hydrobiol 96:191-208 doi: 10.1002/iroh.201011253

Jenkins DG (1995) Dispersal-limited zooplankton distribution and community composition in new ponds. Hydrobiologia 313:15-20 doi: 10.1007/BF00025926

Jenkins DG, Buikema Jr.. AL (1998) Do similar communties develop in similar sites? A test with zooplankton structure and function. Ecol Monogr 68:421-443 doi: 10.1890/00129615(1998)068[0421:DSCDIS]2.0.CO;2

Jiménez JJ, Decaëns T, Lavelle P, Rossi JP (2014) Dissecting the multi-scale spatial relationship of earthworm assemblages with soil environmental variability. BMC Ecology 14:26 doi: 10.1186/s12898-014-0026-4

Juračka PJ, Kořínek V, Petrusek A (2010) A new Central European species of the Daphnia curvirostris complex, Daphnia hrbaceki sp. nov. (Cladocera, Daphniidae). Zootaxa 2718:1-22

Kappes H, Tackenberg O, Haase P (2014) Differences in dispersal- and colonization-related traits between taxa from the freshwater and the terrestrial realm. Aquat Ecol 48:73-83 doi: $10.1007 / \mathrm{s} 10452-013-9467-7$ 
612 Kopáček J, Hejzlar J (1993) Semi-micro determination of total phosporus in fresh waters with

613

614

615

616

617

618

619

620

621

622

623

624

625

626

627

628

629

630

631

632

633

634

635

636 perchloric acid digestion. Int J Environ An CH 53:173-183 doi:

\section{$10.1080 / 03067319308045987$}

Legendre P, Anderson MJ (1999) Distance-based redundancy analysis: Testing multispecies responses in multifactorial ecological experiments. Ecol Monogr 69:1-24 doi: 10.1890/0012-9615(1999)069[0001:DBRATM]2.0.CO;2

Leibold MA et al. (2004) The metacommunity concept: a framework for multi-scale community ecology. Ecol Lett 7:601-613 doi: 10.1111/j.1461-0248.2004.00608.x

Leibold MA, Norberg J (2004) Biodiversity in metacommunities: plankton as complex adaptive systems? Limnol Oceanogr 49:1278-1289 doi:

$$
\text { 10.4319/lo.2004.49.4_part_2.1278 }
$$

Lindo Z, Winchester NN (2009) Spatial and environmental factors contributing to patterns in arboreal and terrestrial oribatid mite diversity across spatial scales. Oecologia 160:817-825 doi: 10.1007/s00442-009-1348-3

Löbel S, Snäll T, Rydin H (2006) Species richness patterns and metapopulation processes evidence from epiphyte communities in boreo-nemoral forests. Ecography 29:169-182 doi: 10.1111/j.2006.0906-7590.04348.x

Louette G, De Meester L (2005) High dispersal capacity of cladoceran zooplankton in newly founded communities. Ecology 86:353-359 doi: 10.1890/04-0403

Louette G, De Meester L, Declerck SAJ (2008) Assembly of zooplankton communities in newly created ponds. Freshwater Biol 53:2309-2320 doi: 10.1111/j.13652427.2008.02052.x

Louette G, Vanoverbeke J, Ortells R, De Meester L (2007) The founding mothers: the genetic structure of newly established Daphnia populations. Oikos 116:728-741 doi: 10.1111/j.0030-1299.2007.15664.x 
637 Luecke C, Litt AH (1987) Effects of predation by Chaoborus flavicans on crustacean

638

639

640

641

642

643

644

645

646

647

648

649

650

651

652

653

654

655

656

657

658

659

660

661

zooplankton of Lake Lenore, Washington. Freshwater Biol 18:185-192 doi:

10.1111/j.1365-2427.1987.tb01306.x

MacArthur RH, Wilson EO (1967) The theory of island biogeography. Princeton University Press, Princeton

Maguire B (1963) The passive dispersal of small aquatic organisms and their colonization of isolated bodies of water. Ecol Monogr 33:161-185 doi: 10.2307/1948560

March F, Bass D (1995) Application of island biogeography theory to temporary pools. J Freshwater Ecol 10:83-85 doi: 10.1080/02705060.1995.9663420

Meisch C (2000) Freshwater Ostracoda of Western and Central Europe. Spektrum Akademischer Verlag, Heidelberg

Michels E, Cottenie K, Neys L, Meester L (2001) Zooplankton on the move: first results on the quantification of dispersal in a set of interconnected ponds. Hydrobiologia 442:117-126 doi: 10.1023/A:1017549416362

Nathan R, Muller-Landau HC (2000) Spatial patterns of seed dispersal, their determinants and consequences for recruitment. Trends Ecol Evol 7:278-285 doi: 10.1016/S01695347(00)01874-7

Ng ISY, Carr CM, Cottenie K (2009) Hierarchical zooplankton metacommunities: distinguishing between high and limiting dispersal mechanisms. Hydrobiologia 619:133-143 doi: 10.1007/s10750-008-9605-8

Oksanen J et al. (2011) vegan: Community Ecology Package. R package, version 1.17-11. http://CRAN.R-project.org/package=vegan

Omesová M (2005) Perloočky a klanonožci (Cladocera et Copepoda, Crustacea) CHKO Kokořínsko [Cladocera and Copepoda (Crustacea) of Kokořínsko Protected Landscape Area] Unpublished manuscript, 10 pp. (in Czech) 
662 Padial AA, Ceschin F, Declerck SAJ, De Meester L, Bonecker CC, Lansac-Tôha FA, 663 Rodrigues L, Luzia CR, Train S, Velho LFM, Bini LM (2014) Dispersal ability 664 determines the role of environmental, spatial and temporal drivers of metacommunity 665 structure. PLoS ONE 9: e111227 doi:10.1371/journal.pone.0111227

666 Paradis E, Claude J, Strimmer K (2004) APE: Analyses of phylogenetics and evolution in R 667 language. Bioinformatics 20:289-290 doi: 10.1093/bioinformatics/btg412

668 Peres-Neto PR, Legendre P, Dray S, Borcard D (2006) Variation partioning of species data 669 matrices: estimation and comparison of fractions. Ecology 87:2614-2625 doi: 10.1890/0012-9658(2006)87[2614:VPOSDM]2.0.CO;2

Proctor VW (1964) Viability of crustacean eggs recovered from ducks. Ecology 45:656-658 doi: $10.2307 / 1936124$

673 Ripley B (2011) tree: Classification and regression trees. R package version 1.0-26

674 Schlichting Jr. HE, Sides SL (1969) The passive transport of aquatic microorganisms by 675 selected hemiptera. J Ecol 57:759-764 doi: 10.2307/2258497

676 Schulz G, Siqueira T, Stefan G, de Oliveira Roque F (2012) Passive and active dispersers 677 respond similarly to environmental and spatial processes: an example from metacommunity dynamics of tree hole invertebrates. Fund Appl Limnol 181:315-326 doi: $10.1127 / 1863-9135 / 2012 / 0365$

Sciullo L, Kolasa J (2012) Linking local community structure to the dispersal of aquatic

Shiel RJ, Green JD, Nielsen DL (1998) Floodplain biodiversity: why are there so many species? Hydrobiologia 387:39-46 doi: 10.1023/A:1017056802001 
687 Shurin JB, Cottenie K, Hillebrand H (2009) Spatial autocorrelation and dispersal limitation in 688 freshwater organisms. Oecologia 159:151-159 doi: 10.1007/s00442-008-1174-z

689

690

691

692

693

694

695

696

697

698

699

700

701

702

703

704

705

706

707

708

709

710

711

Smith TW, Lundholm JT (2010) Variation partitioning as a tool to distinguish between niche and neutral processes. Ecography 33: 648-655 doi: 10.1111/j.16000587.2009.06105.x

Soininen J (2014) A quantitative analysis of species sorting across organisms and ecosystems. Ecology 95: 3284-3292 doi: 10.1890/13-2228.1

Soininen J, Kokocinski M, Estlander S, Kotanen J, Heino J (2007) Neutrality, niches, and determinants of plankton metacommunity structure across boreal wetland ponds. Ecoscience 14: 146-154 doi: 10.2980/1195-6860(2007)14[146:NNADOP]2.0.CO;2

Soons MB, Ozinga WA (2005) How important is long-distance seed dispersal for the regional survival of plantspecies? Diversity Distrib 11:165-172 doi: 10.1111/j.13669516.2005.00148.x

Šrámek-Hušek R (1953) Naši klanonožci [Our copepods] (in Czech), Naše vojsko edn. Nakladatelství československé akademie věd, Praha

Št’astný K, Bejček V, Hudec K (2006) Atlas hnízdního rozšiřrení ptáků v České republice: 2001-2003 Aventinum, Praha

Van de Meutter F, Stoks R, De Meester L (2008) Size-selective dispersal of Daphnia resting eggs by backswimmers (Notonecta maculata). Biol Lett 4:494-496 doi: $10.1098 / \mathrm{rsbl} .2008 .0323$

Vanschoenwinkel B, Gielen S, Vandewaerde H, Seaman M, Brendonck L (2008a) Relative importance of different dispersal vectors for small aquatic invertebrates in a rock pool metacommunity. Ecography 31:567-577 doi: 10.1111/j.0906-7590.2008.05442.x

Vanschoenwinkel B, Waterkeyn A, Vandecaetsbeek T, Pineau O, Grillas P, Brendonck L (2008b) Dispersal of freshwater invertebrates by large terrestrial mammals: a case 
study with wild boar (Sus scrofa) in Mediterranean wetlands. Freshwater Biol 53:2264-2273 doi: 10.1111/j.1365-2427.2008.02071.x

714 Verreydt D, De Meester L, Decaestecker E, Villena MJ, Van Der Gucht K, Vannormelingen P, Vyverman W, Declerck SAJ (2012) Dispersal-mediated trophic interactions can generate apparent patterns of dispersal limitation in aquatic metacommunities. Ecol Lett 15:218-226 doi: 10.1111/j.1461-0248.2011.01728.x

Viana DS et al. (2014) Environment and biogeography drive aquatic plant and cladoceran species richness across Europe. Freshwater Biol 59:2096-2106 doi: 10.1111/fwb.12410

Waterkeyn A, Pineau O, Grillas P, Brendonck L (2010) Invertebrate dispersal by aquatic mammals: a case study with nutria Myocastor coypus (Rodentia, Mammalia) in Southern France. Hydrobiologia 654:267-271 doi: 10.1007/s10750-010-0388-3

Yan ND, Keller W, MacIsaac HJ, McEachern LJ (1991) Regulation of zooplankton community structure of an acidified lake by Chaoborus. Ecol Appl 1:52-65 doi: $10.2307 / 1941847$

Zhai M, Nováček O, Výravský V, Syrovátka V, Bojková J, Helešic J. (2015) Environmental and spatial control of ostracod assemblages in the Western Carpathian spring fens. Hydrobiologia 745: 225-239 doi: 10.1007/s 10750-014-2104-1 
730

731

732

733

734

735

736

737

738

739

740

741

742

743

744

745

746

747

748

749

750

751

752

753

754

\section{CAPTIONS OF FIGURES AND SUPPLEMENTARY MATERIAL:}

Fig. 1: Position of the studied localities $(n=42)$ within the heterogeneous landscape, and their affiliation to spatial clusters $(n=6)$ defined by pool geographical position in relation to deep canyons representing potential barriers for dispersal vectors, and by connectivity by streams.

The small inset map shows the position of the studied area within the river network of the Czech Republic

Fig. 2: Venn diagram with variation partitioning results of microcrustacean species composition explained by: a) three spatial variable categories (i.e., affiliation of pools to a priori defined clusters, the number of other lentic habitat within a radius of $3 \mathrm{~km}$, and principal coordinates of the 'valley' distance dissimilarity matrix); b) three variable categories representing spatial context, pool characteristics, and invertebrate predator richness. ${ }^{* *}$ : values significant at the 0.005 level; *: 0.05 level (tested with partial RDA at 200 permutations)

Fig. 3: Relationship between the invertebrate predator species richness and pool surface area

Fig. 4: a) Regression tree identifying the most important variables influencing the microcrustacean species richness within each of the studied pools. This tree explains $63.7 \%$ of the variation in species richness. Boxplots under each tree node compare species richness between groups of the pools defined by these nodes. b) Relationship between species richness and the most important variables selected in the regression tree

Fig. 5: Microcrustacean species richness in experimental pools $(n=20)$ in a meadow within the study area, since their creation in August 2007 until December 2008. Whiskers above the 
755 line showing species richness per pool indicate standard errors of the mean. The dashed line

756 represents the number of species actually observed in all experiment pools for the specific

757 month, while the grey line shows a cumulative curve of the same number 



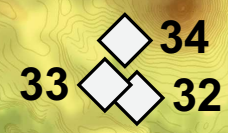

$>_{31}$

$>30$
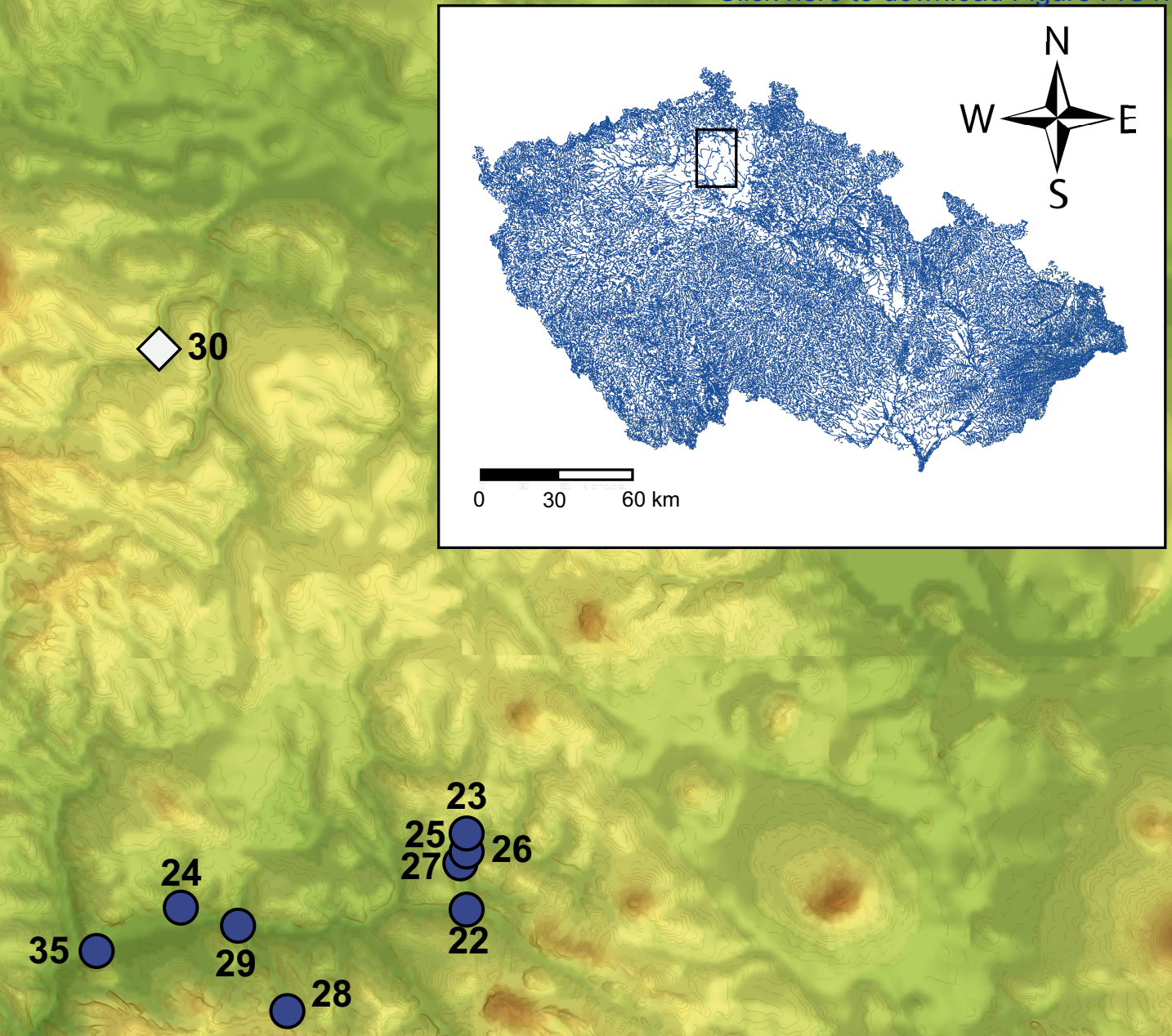

$36 \bigcirc$

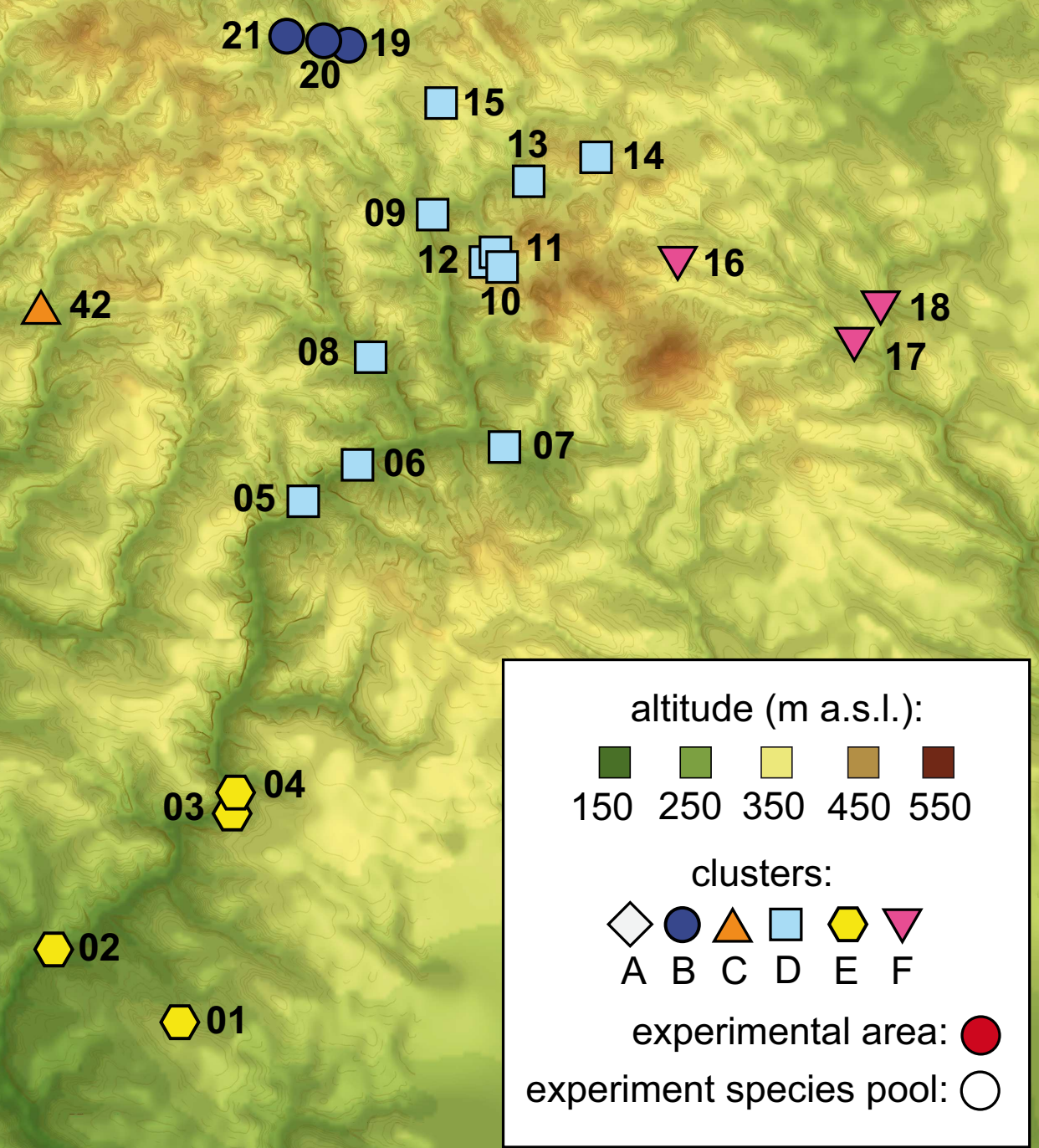

$\triangle 42$

$\triangle 37$

$41 \triangle$

Op2

Op1

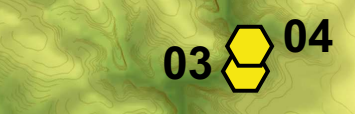

$\square 02$

\section{$\square 01$}


a)

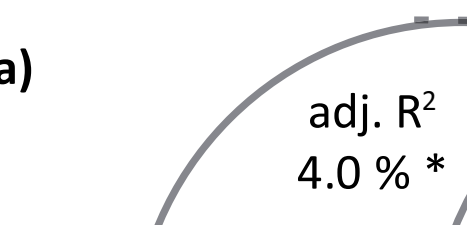

clusters

adj. $R^{2} 2.2 \%$ *

$4.0 \%$ *

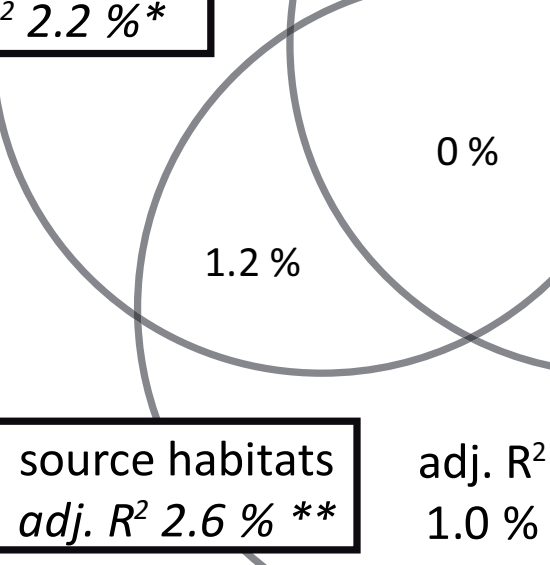

Model adj. R2 $11.7 \%$ adj. $\mathrm{R}^{2}$

$6.7 \% * *$

$0 \%$

\section{$6.7 \% * *$}

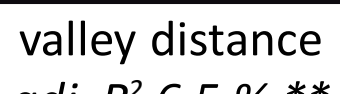

adj. $R^{2} 6.5 \%$ **

$\%$

$1.7 \%$

$1.0 \%$ b)

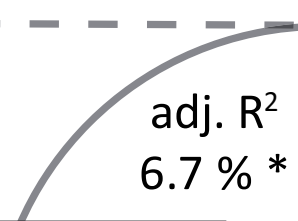

adj. $\mathrm{R}^{2}$

$6.7 \%$ *

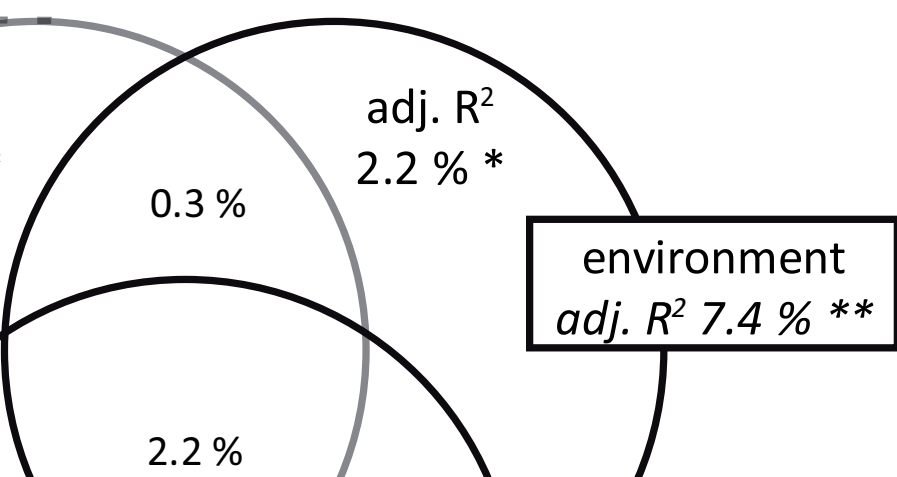

$2.2 \%$

$2.5 \%$

$\%$

spatial context
adj. $R^{2} 11.7 \% * *$

$2.2 \%$

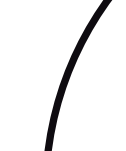

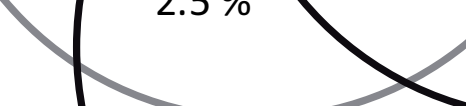
adj. $R^{2}$ $0 \%$

predators adj. $R^{2} 6.7 \%$ **

Model adj. $\mathrm{R}^{2}$ 16.0\%** 
Qlick here to download Figure FIG3.eps $\underline{\underline{ \pm}}$

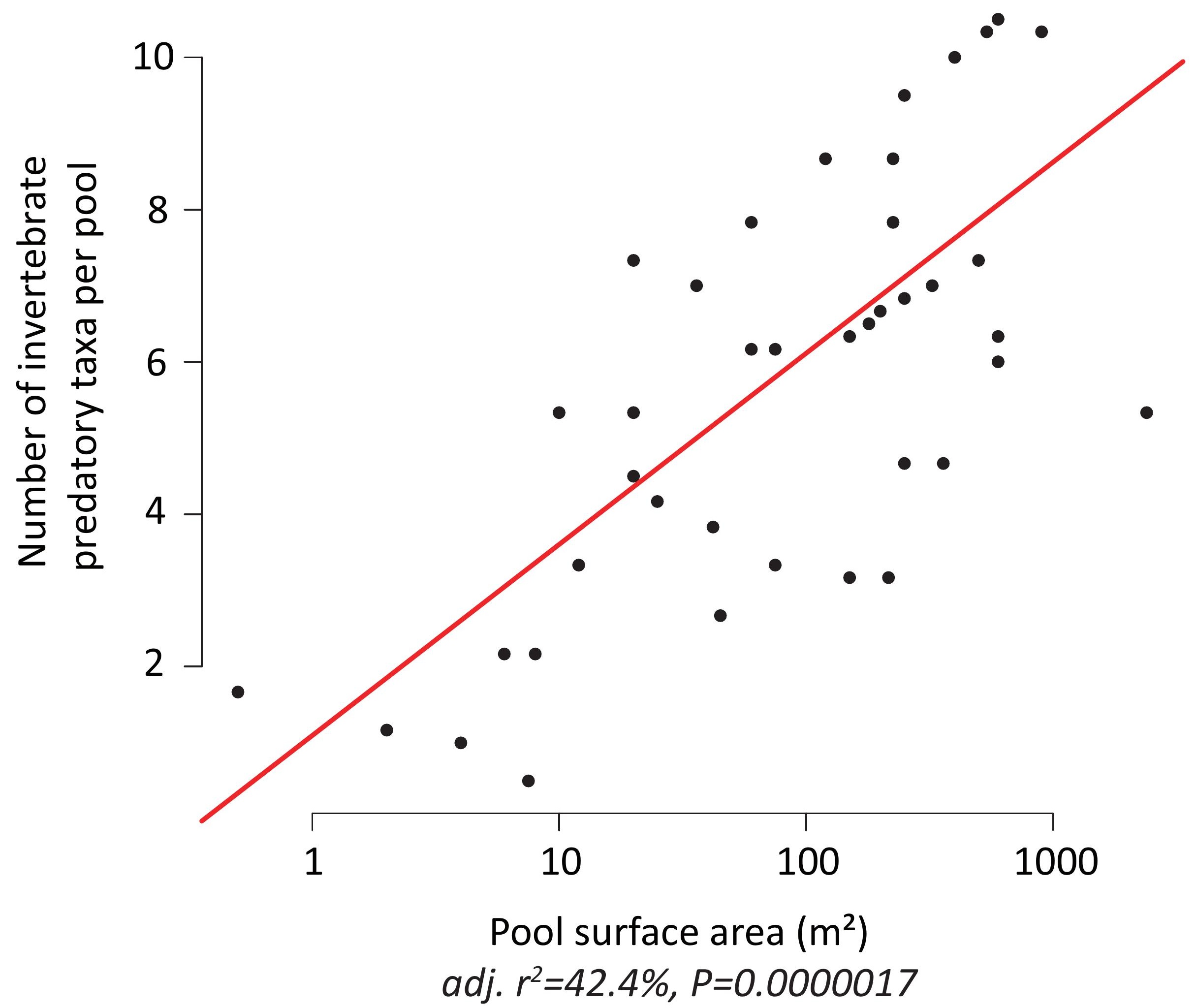


a)

b)
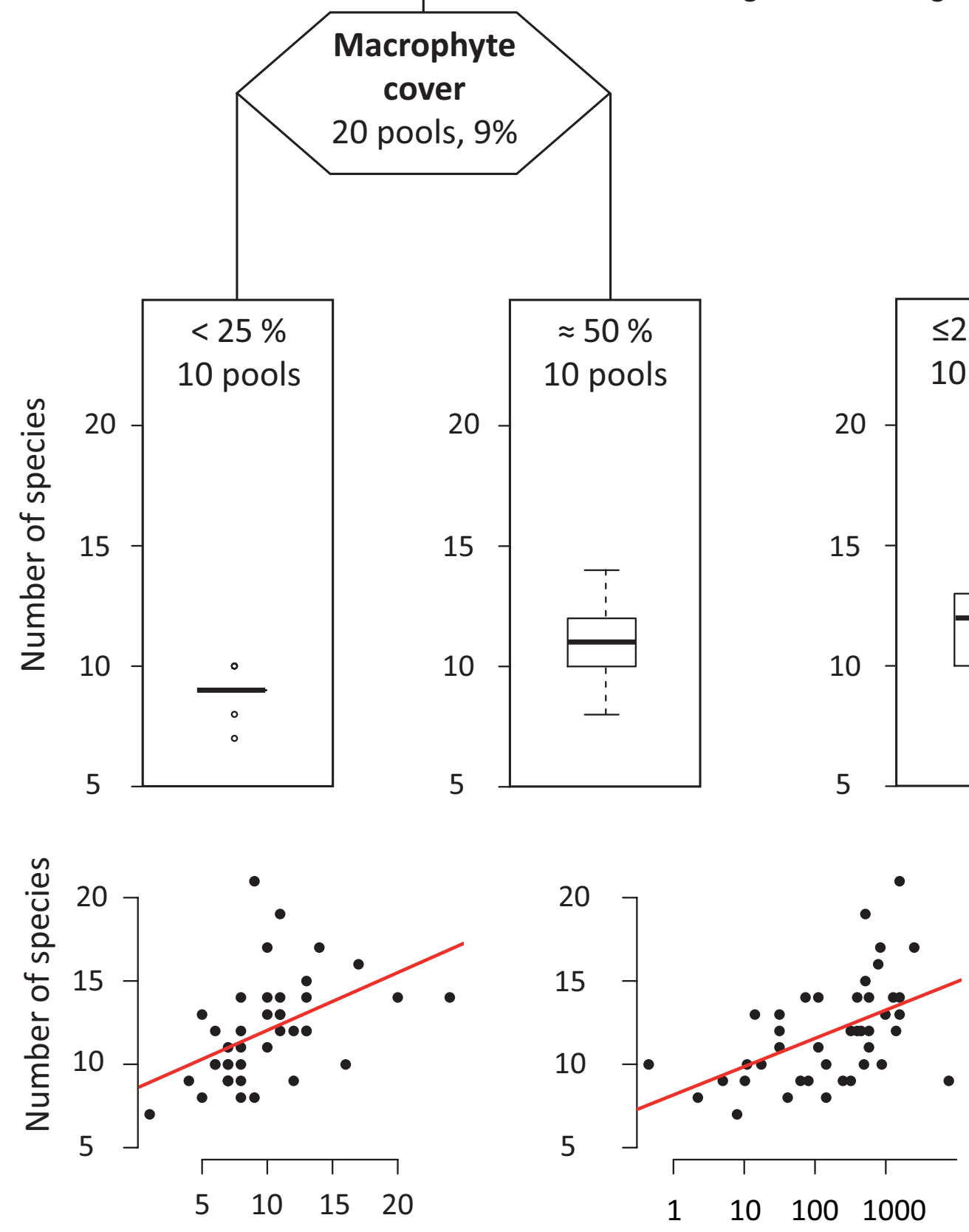

Lentic aquatic habitats within $3 \mathrm{~km}$ adj. $r^{2}=20.8 \%, P=0.0014$

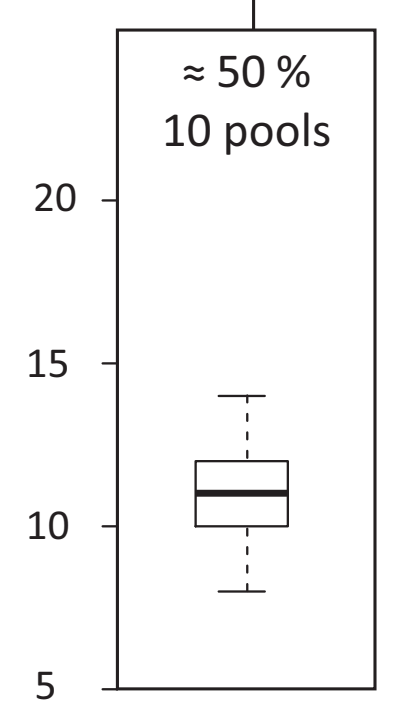

Lentic aquatic

habitats within $3 \mathrm{~km}$
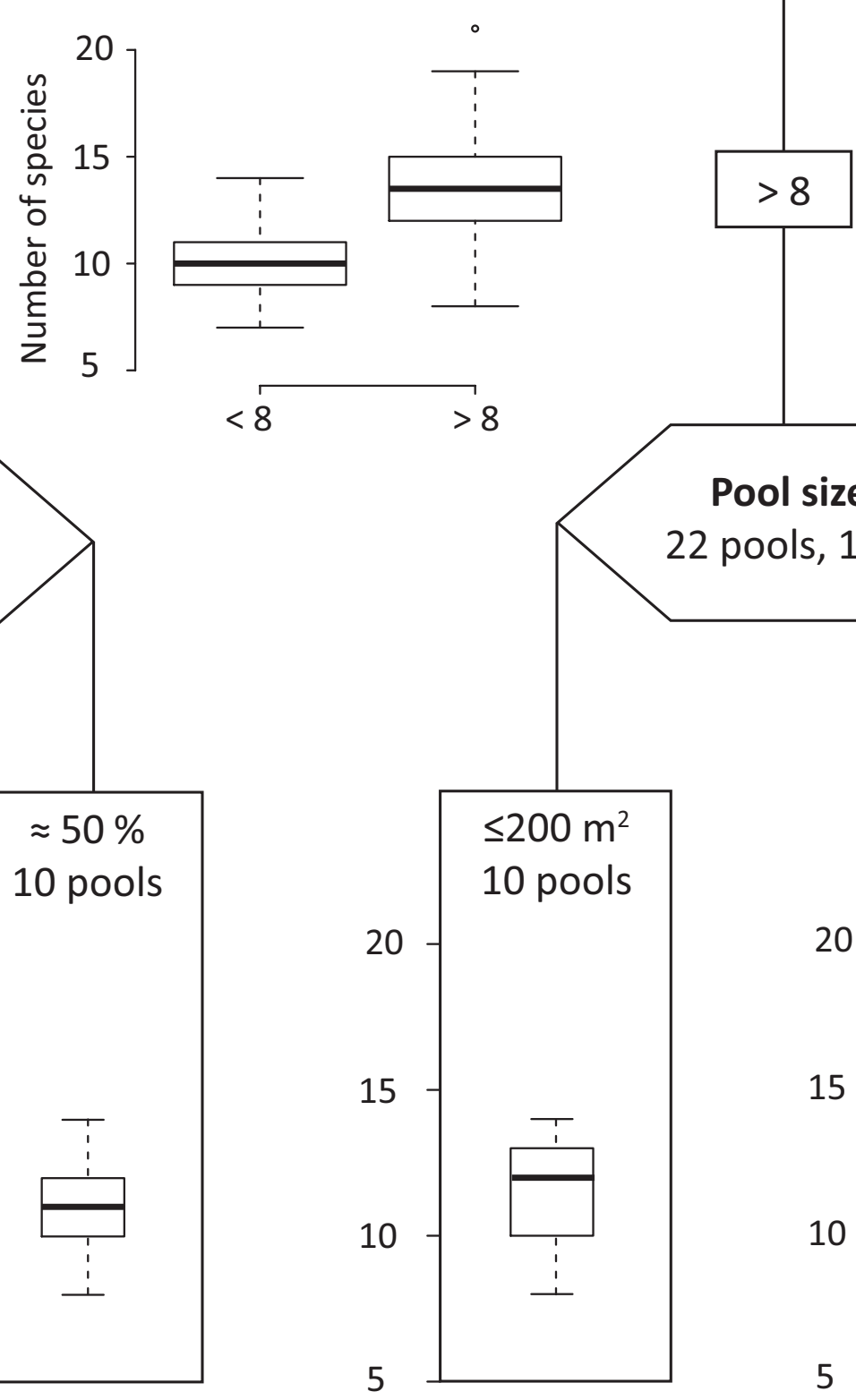

Pool size

22 pools, $18 \%$

Pool size $\left(\mathrm{m}^{2}\right)$

adj. $r^{2}=23.2 \%, P=0.0007$

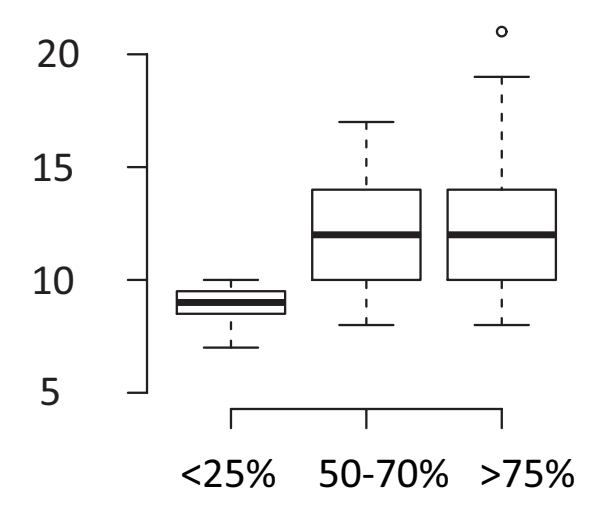

Macrophyte cover adj. $r^{2}=17.4 \%, P=0.0034$ 


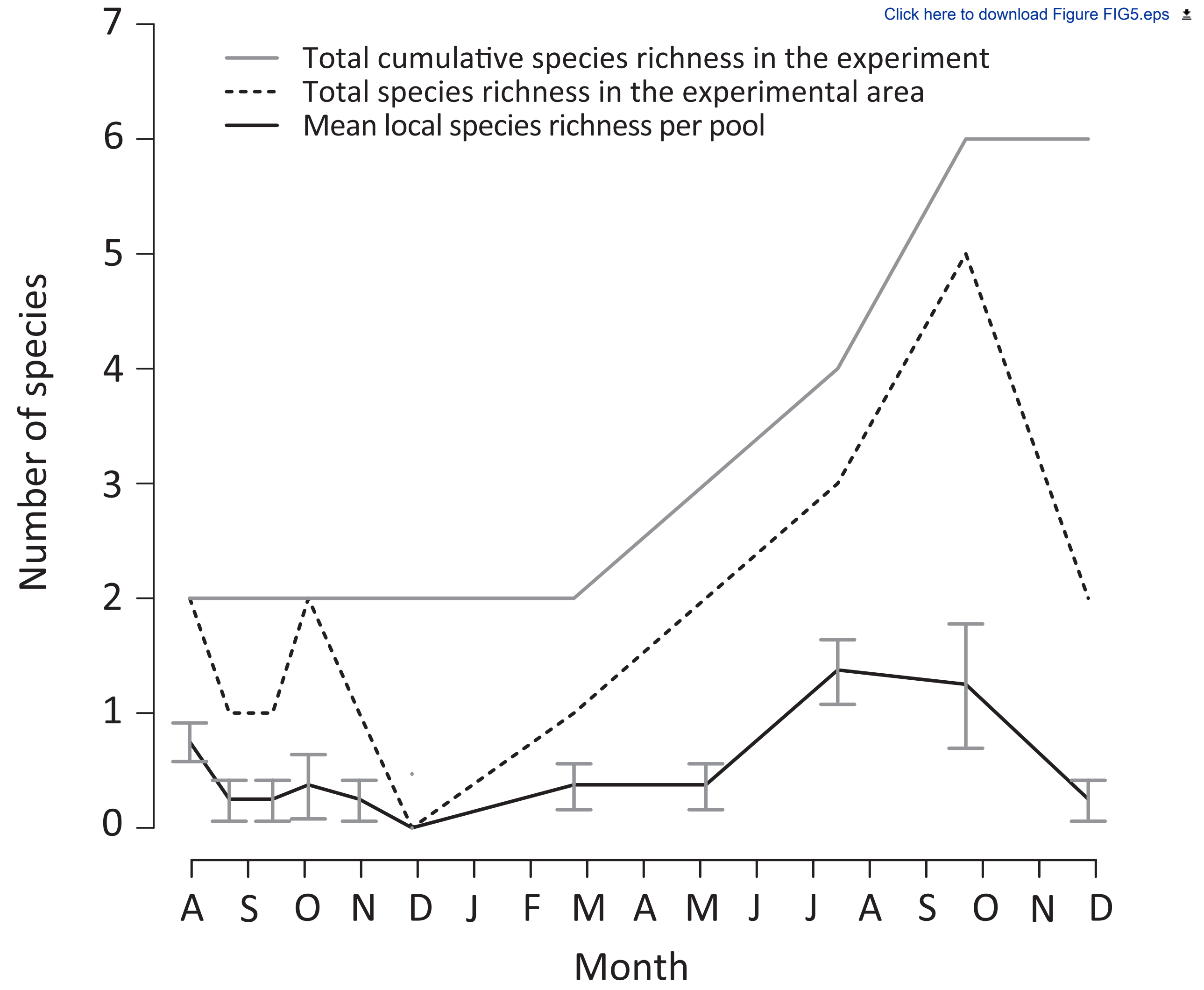


Click here to access/download Supplementary Material Juracka et al. ESM.pdf 